\title{
Assessment of the Characteristics and Influencing Factors of Ozone in Fuzhou, China, Using Wavelet Analysis
}

\author{
Guiwen Luo', Lanyi Zhang ${ }^{1}$, Xisheng Hu${ }^{1}$, Benjie Shi ${ }^{2}$, Rongzu Qiu ${ }^{1 *}$ \\ ${ }^{1}$ College of Transportation and Civil Engineering, Fujian Agriculture and Forestry University, Fuzhou 350002, China \\ ${ }^{2}$ School of Traffic engineering, Fuzhou Polytechnic, Fuzhou 350002, China
}

\begin{abstract}
In recent years, ozone $\left(\mathrm{O}_{3}\right)$ air pollution has become a major problem - which is still increasing - in China. In this study, data on the $\mathrm{O}_{3}$ concentration as well as on two of its influencing factors, meteorological parameters and traffic conditions, were collected in Fuzhou and then analyzed via wavelet transforms to evaluate the variation in $\mathrm{O}_{3}$ concentration and its relationships with the factors. High concentrations appeared during spring and summer, and notable fluctuations occurred primarily from March till April, from June till July and during September. The level of $\mathrm{O}_{3}$ exhibited significant positive correlations with the temperature and sunshine duration but negative ones with the relative humidity, precipitation and air pressure; additionally, it increased when the wind speed was low and fluctuated when the wind speed was high. The concentration was also significantly negatively correlated with the concentrations of $\mathrm{O}_{3}$ precursors $\left(\mathrm{NO}_{x}\right.$ and $\left.\mathrm{CO}\right)$ and hence closely related to the traffic conditions, as the reduced vehicle speed during rush hour due to increased vehicle flow and traffic density led to higher precursor emissions in the vehicular exhaust. A prominent "weekend effect" was observed with the precursor levels, which displayed greater fluctuations during the weekdays than the weekends; the vehicle flow and the $\mathrm{O}_{3}$ concentration.
\end{abstract}

Keywords: Ozone concentrations; Wavelet analysis; Meteorological parameters; Gas precursor; Traffic parameters.

\section{INTRODUCTION}

With the acceleration of industrialization and urbanization, the air pollution problems have drawn unprecedented attention of the society in China. In recent years, the surface ozone $\left(\mathrm{O}_{3}\right)$ has replaced inhalable particles $\left(\mathrm{PM}_{10}\right)$ and fine particulate matter $\left(\mathrm{PM}_{2.5}\right)$ as the primary pollutant in many Chinese cities.

Tropospheric $\mathrm{O}_{3}$ is a secondary air pollutant, which is produced by the photochemical reaction involving $\mathrm{NO}_{x} \mathrm{NO}$ and $\mathrm{NO}_{2}$ ) and volatile organic compounds (VOCs) in the presence of sunlight. At a height of $10-50 \mathrm{~km}$, stratospheric $\mathrm{O}_{3}$ forms a gas shield around the earth which can absorb solar ultraviolet radiation. However, the tropospheric $\mathrm{O}_{3}$ can stimulate and damage mucosal tissues, such as the eyes and respiratory system, and hinder blood oxygen transmission, which will do harm to human health (Jung et al., 2016).

To date, $\mathrm{O}_{3}$ pollution has been found in most of Chinese areas, such as Beijing-Tianjin-Hebei region (BTH) (Li et al., 2015; Li et al., 2020), the Pearl River Delta (PRD) Zheng et al., 2010; Lin et al., 2019) and the Yangtze River

\footnotetext{
* Corresponding author.

E-mail address: fafuqrz@126.com
}

Delta (YRD) (Wu et al., 2017; Liu et al., 2018). To reduce $\mathrm{O}_{3}$ pollution, many measures have been taken by the Chinese government. During the $12^{\text {th }}$ Five-Year Plan period (2011-2015), the nitrogen oxides were included as indicators of air quality, and VOCs were included in the total control range during the $13^{\text {th }}$ Five-Year Plan period (2016-2020). Moreover, the VOC Pollution Prevention and Control Plan in the $13^{\text {th }}$ Five-Year Plan was issued by the Ministry of Environmental Protection of the People's Republic of China (MEP) on September 19, 2017.

A number of $\mathrm{O}_{3}$-related pollution studies have been conducted in recent years, including pollution process and source identification of $\mathrm{O}_{3}$ (Tong et al., 2018; Wang et al., 2019), the effect of ozone on crops and human (Feng et al., 2015; Pun et al., 2019), the spatial and temporal variations of $\mathrm{O}_{3}$ concentrations (Cheng et al., 2018; Ercan et al., 2019; Zhang et al., 2020), the relationship between surface $\mathrm{O}_{3}$ concentrations and meteorological conditions (Wang et al., 2017; Qiao et al., 2019), and the precursors and their contributions to $\mathrm{O}_{3}$ (Zhang et al., 2008). However, most of these studies were restricted to the overall change characteristics of $\mathrm{O}_{3}$, there are few researches about mutation characteristic. Therefore, the wavelet analysis method was introduced. Compared with traditional methods, wavelet analysis can quickly find the mutation characteristics of time series. Moreover, the wavelet coherence spectrum can 
reflect both the correlation and time lag between variables which makes up the shortage of the traditional correlation analysis method (such as Pearson, Spearman and Kendall). Besides, traffic is a significant source of $\mathrm{O}_{3}$ (Colvile et al., 2001), but very limited studies have analyzed the relationship between $\mathrm{O}_{3}$ concentrations and traffic parameters (such as vehicle flow, vehicle speed and traffic flow density). Finally, researches on $\mathrm{O}_{3}$ have given priority to the developed areas such as BTH, PRD, and YRD, but there are relatively few studies on $\mathrm{O}_{3}$ in the second tier and third tier cities, whose $\mathrm{O}_{3}$ pollution is prominent day by day.

Fuzhou is the capital of Fujian Province, a second tier city, one of the Chinese open coastal port cities and one of the starting cities of the Maritime Silk Road. With the fast growth of the economy and society, the $\mathrm{O}_{3}$ pollution has attracted the attention of the Fuzhou municipal government and the public. From 2015 to 2018, the average annual concentration of $\mathrm{O}_{3}$ has increased from 79 to $96 \mu \mathrm{g} \mathrm{m}^{-3}$, approaching Grade I of the national standard. To cope with this, the environmental protection departments issued many policies, such as the $\mathrm{O}_{3}$ Pollution Prevention and Control Plan (2018), the Blue Sky Action Plan of Fuzhou and "Accelerate elimination of vehicles with yellow license plates" (Zhang et al., 2018). However, there are very limited studies on $\mathrm{O}_{3}$ pollution in Fuzhou.

In this study, the time series of $\mathrm{O}_{3}$ concentrations was decomposed and reconstructed by wavelet transform, and the variation characteristics of $\mathrm{O}_{3}$ concentrations in Fuzhou were analyzed, to account for the fluctuations of $\mathrm{O}_{3}$ concentrations. In this paper the correlation between $\mathrm{O}_{3}$ concentrations and main influence factors such as meteorological conditions, gaseous precursors and traffic condition based on wavelet coherence were further analyzed. Consequently, the results are helpful for government departments to formulate pollution prevention strategies based on understanding the $\mathrm{O}_{3}$ variation characteristics and influence factors. In addition, the analysis on traffic parameters and $\mathrm{O}_{3}$ concentrations can provide a basis for the formulation of transportation management policy, including transportation demand management (TDM) and transportation system management (TSM), to achieve emission reduction goals.

\section{MATERIALS AND METHODS}

\section{Study Sites}

Fuzhou is located in the eastern coast of Fujian Province, at $26^{\circ} 4^{\prime} 48^{\prime \prime} \mathrm{N}$ latitude, $119^{\circ} 18^{\prime} \mathrm{E}$ longitude with an average elevation of $80 \mathrm{~m}$. It covers an area of $11,968 \mathrm{~km}^{2}$, and the urban area is $1,219.37 \mathrm{~km}^{2}$. The landform of Fuzhou is estuary basin (roughly similar to Los Angeles, CA, USA), and the existing forest cover percentage has reached $57.26 \%$ (up to March 2019), which occupies second place in provincial capital cities.

In recent years, with the development of economy and acceleration of urbanization, Fuzhou has become a modern city and the central city of West Taiwan Strait City Belt. The population of Fuzhou has increased continuously from 6.74 million in 2014 to 7.74 million in 2018. The car ownership had reached 1.55 million at the end of 2018 , increasing by $31.2 \%$ over the end of 2017 . The industrial energy consumption was 15.36 million tons of standard coal and the electricity consumption increased by $21.7 \%$ in 2018 (Bureau of Statistics of Fuzhou, 2018). Due to the rapid urbanization, the resources and environmental problems become increasingly prominent.

As to the climate conditions, the climate in Fuzhou is subtropical monsoon climate. The annual average sunshine duration varies from 1,700 hours to 1,980 hours, the annual average rainfall varies from $900 \mathrm{~mm}$ to $2,100 \mathrm{~mm}$. The annual average temperature ranges from $20^{\circ} \mathrm{C}$ to $25^{\circ} \mathrm{C}$, the predominant wind direction is the northeaster and partial south wind is boosted up during the period from June to August (Zhang et al., 2018).

Currently, Fuzhou has six national air quality monitoring stations (Fig. 1), the spatial distribution, monitored frequency, and so on are illustrated in our previous study (Zhang et al., 2018).

\section{Data Sources}

For this study, the daily mean data of air pollutant (includes $\mathrm{NO}_{2}, \mathrm{CO}$ and $\mathrm{O}_{3}$ ) corresponding to the period 2017 to 2018 have been collected from the website of the China National Environmental Monitoring Centre (CNEMC) (http://www.cnemc.cn). According to the requirements of the National Ambient Air Quality Standards (GB 3095-2012), the maximum daily 8-hour average (MDA8) $\mathrm{O}_{3}$ concentration was used as a criterion for evaluating the $\mathrm{O}_{3}$ pollution level, and the value of primary standards $\left(100 \mu \mathrm{g} \mathrm{m}^{-3}\right)$ was used to judge whether the $\mathrm{O}_{3}$ concentration exceeded limits. Moreover, the VOCs had a certain influence on the process of photochemical reaction, but they were not monitored by CNEMC, so VOC data were not used in this study.

The meteorological parameters data, including temperature, sunshine duration, relative humidity, precipitation, air pressure and wind speed, were derived from the website of National Meteorological Center (NMC) (http://www.nmc.cn).

In addition, to analyze the relationship between $\mathrm{O}_{3}$ concentration and traffic parameters, the vehicle flow data were acquired from video monitoring, and the vehicle speed data were derived from laser Doppler anemometry (LDA) devices installed on the monitoring road segment.

\section{Wavelet Transform}

\section{The Continuous Wavelet Transform}

To analyze the mutation characteristic, the time series of $\mathrm{O}_{3}$ concentration was decomposed and reconstructed by the continuous wavelet transform (CWT). The CWT is defined as:

$$
\begin{aligned}
& W T_{f}(a, \tau) \leq f(t), \psi_{a, t}(t) \geq \frac{1}{\sqrt{a}} \int_{R} f(t) \overline{\psi\left(\frac{t-\tau}{a}\right) d t} \\
& \psi_{a, t}(t)=|a|^{-\frac{1}{2}} \psi\left(\frac{t-\tau}{a}\right)
\end{aligned}
$$

where $W T_{f}(a, \tau)$ is wavelet coefficients, $a$ is scale parameter, 


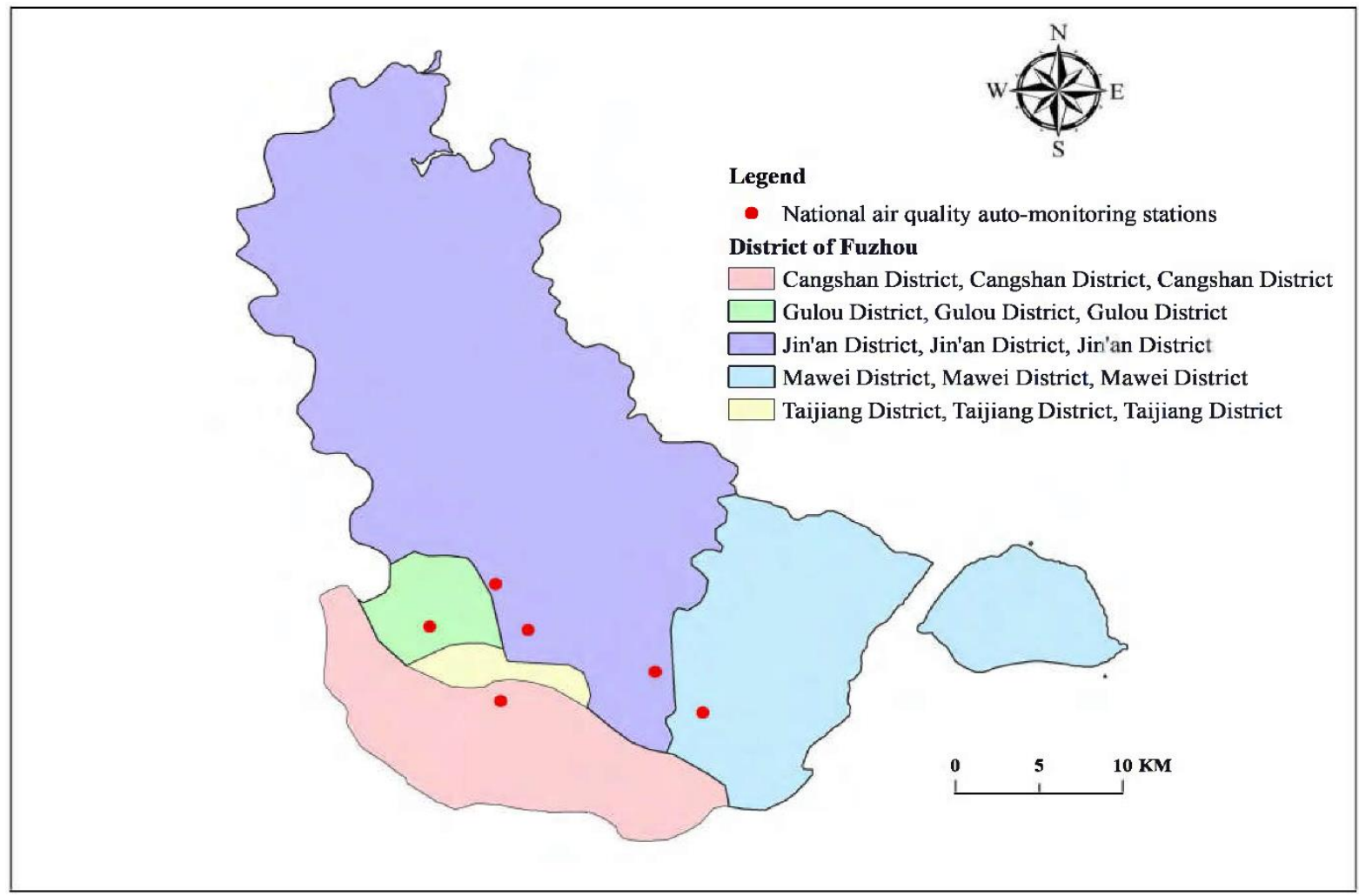

Fig. 1. Location of national air quality auto-monitoring stations in Fuzhou.

$\tau$ is translation parameter, $t$ is time and $\psi_{a, \tau}(t)$ is the wavelet basis function.

Considering the characteristics of data and the analysis request, the Morlet and Daubechies were used in this paper.

\section{Morlet Wavelet}

The Morlet wavelet is defined as:

$\psi_{0}(\eta)=\pi^{-1 / 4} e^{i \omega_{0} \eta} e^{-\frac{1}{2} \eta^{2}}$

where $\omega_{0}$ is dimensionless frequency and $\eta$ is dimensionless time.

\section{Daubechies Wavelet}

The series of Daubechies wavelet is abbreviated as "dbN," where $N$ is order. The Daubechies wavelet has no analytic expression, in addition to db1 (which equal to Haar) and it is defined as:

$$
\psi=\left\{\begin{array}{cl}
1, & 0 \leq x \leq \frac{1}{2} \\
-1, & \frac{1}{2} \leq x \leq 1 \\
0, & \text { elsewise }
\end{array}\right\}
$$

\section{The Cross Wavelet Transform}

The relationship between two time series $\left(\mathrm{O}_{3}\right.$ concentration and meteorological parameters) can be found by analyzing the time-frequency domain over multiple time scales. Defining $W_{x}(s)$ and $W_{y}(s)$ as the wavelet transform of two time series ( $X$ and $Y, s$ means time), and the cross wavelet transform (XWT) can be defined as:

$$
W_{n}^{X Y}(S)=W_{n}^{X}(S) \overline{W_{n}^{Y}(S)}
$$

The density of cross wavelet spectrum is defined as $\left|W_{n}{ }^{X Y}(S)\right|$ ( $n$ means the length of time series), which means that the two time series have a common wavelet energy, and the correlation becomes more significant as this value increases.

The cross wavelet spectrum can be verified by comparison with the red noise standard spectrum. If the red noise significance test is passed, the two sequences are considered to have a good correlation, otherwise the correlation is not significant. The red noise standard spectrum of two time series with $P_{k}{ }^{X}$ and $P_{k}^{Y}$ is given, and the theoretical distribution of the cross wavelet power can be defined as:

$$
\frac{\left|W_{n}^{X}(S)\right| \overline{W_{n}^{X}(S)} \mid}{\sigma_{X} \sigma_{Y}}=\frac{Z_{V}(p)}{v} \sqrt{P_{k}^{X} P_{k}^{Y}}
$$

where $\sigma_{X}$ and $\sigma_{Y}$ are the standard deviation of two time series, $Z_{v}(p)$ is the confidence level, $v$ is the degree of freedom using Morlet wavelet. For example, the $Z_{V}(0.95)=$ 3.99 is calculated in the $5 \%$ significance level. 
Cross Wavelet Phase Angle

The $\mathrm{O}_{3}$ concentration is not completely synchronized with the variation of meteorological parameters, so the cross wavelet phase angle is introduced to describe the time lag of time series. Within the cone of influence (abbreviated as "COI," and the confidence is 95\%), the phase angle can quantitatively describe the phase relationship. The mean phase angle of a set of angles $a_{i}(i=1, \ldots, n)$ is defined as:

$$
\bar{a}=\arg (\bar{x}, \bar{y}) \text { with } \bar{x}=\sum_{i=2}^{n} \cos \left(a_{i}\right) \text { and } \bar{y}=\sum_{i=2}^{n} \sin \left(a_{i}\right)
$$

\section{Wavelet Coherence}

The wavelet coherence (WTC) spectrum is used to analyze the correlation between $\mathrm{O}_{3}$ concentration and meteorological parameters. The wavelet coherence spectrum can be illustrated as:

$$
R_{n}^{2}(s)=\frac{\left|S\left(s^{-1} W_{n}^{X Y}(s)\right)\right|^{2}}{S\left(s^{-1}\left|W_{n}^{X}(s)\right|^{2}\right) \cdot S\left(s^{-1}\left|W_{n}^{Y}(s)\right|^{2}\right)}
$$

$$
S(W)=S_{\text {scale }}\left(S_{\text {time }}(W(a, \tau))\right)
$$

where $S(W)$ is a smoothing operator, $S_{\text {scale denotes smoothing }}$ along the wavelet scale axis and $S_{\text {time }}$ denotes smoothing in time. A suitable smoothing operator for the Morlet wavelet is given as follows:

$$
\begin{aligned}
& \left.S_{\text {time }}(W)\right|_{s}=\left.\left(W_{n}(s) \times c_{1}^{\frac{-t^{2}}{2 s^{2}}}\right)\right|_{s} \\
& \left.S_{\text {time }}(W)\right|_{s}=\left.\left(W_{n}(s) \times c_{2} \Pi(0.6 s)\right)\right|_{n}
\end{aligned}
$$

where $\Pi$ is the rectangle function, $c_{1}$ and $c_{2}$ are normalization constants, and the factor of 0.6 is the empirical scale for the Morlet wavelet.

In addition, the significance test of wavelet coherence spectrum was performed by Monte Carlo method in this study. And the mean phase angle and 95\% confidence interval drawn in this paper are for wavelet coherence spectrum, and only the arrows with $R_{n}{ }^{2} \geq 0.5$ are marked in wavelet coherence spectrum.

\section{Traffic Parameters}

To explore the relationship between traffic and $\mathrm{O}_{3}$ pollution, the traffic parameters were introduced in this study. In traffic engineering, vehicle flow, vehicle speed and traffic flow density are the basic parameters of traffic flow characteristics. The basic relation between parameters is:

$$
Q=V K
$$

where $Q$ is vehicle flow, $V$ is vehicle speed, and $K$ denotes traffic flow density.

\section{RESULTS AND DISCUSSION}

\section{Characteristic Analysis \\ Annual Variation Characteristic}

According to the trend between $\mathrm{O}_{3}$ concentration and meteorological parameters, one year is divided into four seasons: spring (March-May), summer (June-August), autumn (September-November), and winter (DecemberFebruary). The MDA8 $\mathrm{O}_{3}$ concentrations in 2018 are shown in Fig. 2, ranging from 16 to $201 \mu \mathrm{g} \mathrm{m}^{-3}$.

Fig. 2 shows $\mathrm{O}_{3}$ mass concentration variation has the characteristics of instability, nonlinearity and multiple time scales, which are higher in spring and summer, lower in autumn and winter, ranging from 20 to $201 \mu \mathrm{g} \mathrm{m}^{-3}$ and from 16 to $176 \mu \mathrm{g} \mathrm{m}^{-3}$, respectively. The $\mathrm{O}_{3}$ concentration exhibits multiple-peak distributions and averages $96 \mu \mathrm{g} \mathrm{m}^{-3}$ (slightly lower than the Grade I national standards for air quality). More specifically, the mean $\mathrm{O}_{3}$ concentrations during spring, summer, autumn and winter are $118 \mu \mathrm{g} \mathrm{m}^{-3}, 104 \mu \mathrm{g} \mathrm{m}^{-3}$, $92 \mu \mathrm{g} \mathrm{m}^{-3}$ and $69 \mu \mathrm{g} \mathrm{m}^{-3}$, respectively, and the numbers of days exceeding the value of primary standards are $65 \mathrm{~d}$ (accounted for 41\%), $51 \mathrm{~d}$ (accounted for $31 \%$ ), $37 \mathrm{~d}$ (accounted for 24\%) and $7 \mathrm{~d}$ (accounted for 4\%), respectively.

Such an asymmetric distribution may be explained by various reasons. Firstly, Fuzhou was affected by the monsoon climate, the average daily temperature and light intensity reached higher value, which has proved to be advantageous for photochemical reaction. However, both temperature and light intensity were lower in winter, so that the photochemical reaction rate maintained at a low level. Secondly, there was a development process of atmospheric convection, increased gradually in spring and early summer, reached the peak in summer, slowed down after summer, the tropopause folding often induces the exchange of stratospheric and tropospheric when atmospheric convection reached its peak, and $\mathrm{O}_{3}$ was transported vertically downward to near the ground which caused an increase in near-surface ozone concentration. In addition, lower wind speed, less rainfall and weaker sunshine duration in autumn and winter can leads to the poor atmospheric diffusion conditions.

Furthermore, Fig. 2 indicates significant fluctuations of $\mathrm{O}_{3}$ concentration on following months: March-April, JuneJuly and September. This phenomenon may be caused by the following reasons. To mention first, the rainy season in Fuzhou was mainly concentrated March-April and JuneJuly, and the fluctuations in September were mainly affected by typhoon weather. Less solar radiation and lower temperature during the rainy or cloudy days were not conducive to the process of photochemical reaction, and lower concentration of $\mathrm{NO}_{x}$, VOCs and other precursors results in the decrease of $\mathrm{O}_{3}$ generation.

\section{Mutation Characteristic}

The variation characteristic in mutation days may contain more information related to influencing factors, so the wavelet transform was used to analyze further. The db1 wavelet has good regularity and it can detect the mutation 


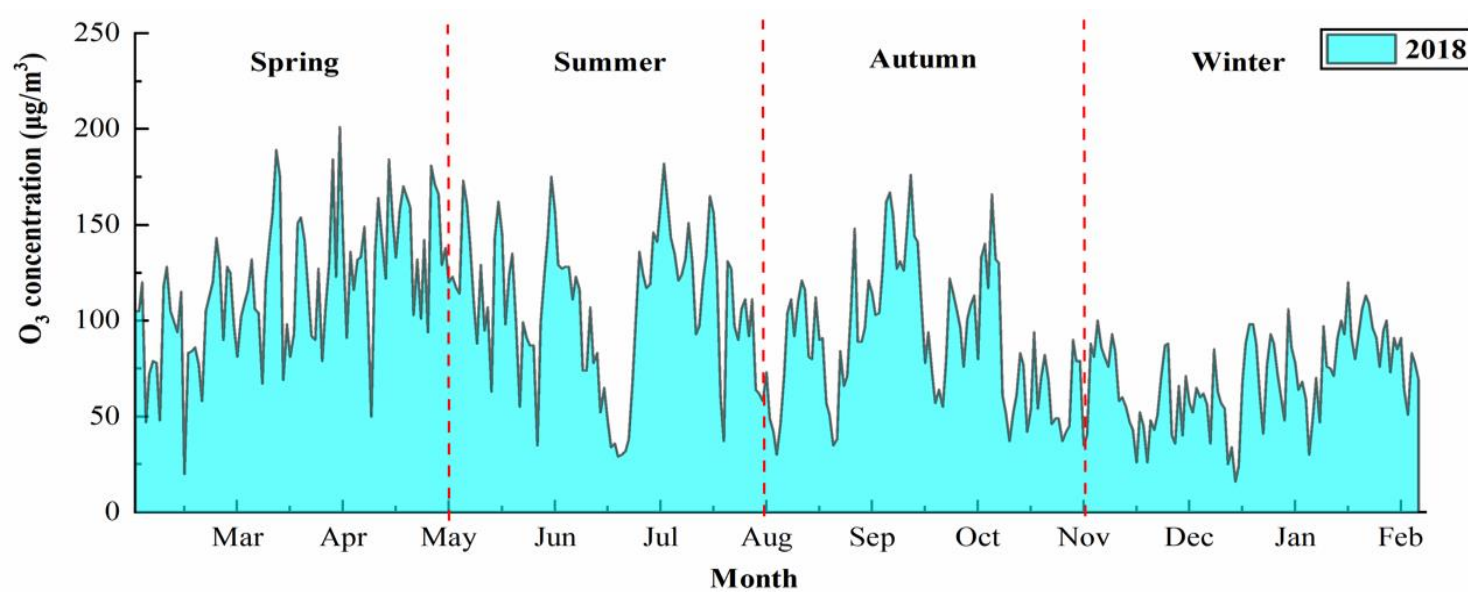

Fig. 2. Diurnal variations of $\mathrm{O}_{3}$ concentration in 2018.

points of time series accurately, so db1 wavelet was selected to conduct decomposition (decomposition level: 4 levels) for the concentration time series (Weng et al., 2011).

Fig. 3 shows the high frequency signal at first level and second level, as well as the position of mutation point (the specific position can be identified by enlarging the detail map with MATLAB). The numbers of days corresponding to the mutation points are $74 \mathrm{~d}, 102 \mathrm{~d}, 127 \mathrm{~d}, 143 \mathrm{~d}, 161 \mathrm{~d}$ and $227 \mathrm{~d}$, respectively, and the corresponding specific dates with meteorological data are shown in Table 1.

The mutation of $\mathrm{O}_{3}$ concentration was the role of comprehensive factors, mainly including human activities and meteorological factors (Steiner et al., 2002). The ozone precursors $\left(\mathrm{NO}_{x}, \mathrm{CO}\right.$ and VOCs) from human activities can be converted into $\mathrm{O}_{3}$ by photochemical reactions. Furthermore, meteorological factors also have an important impact on the mutation of $\mathrm{O}_{3}$ concentration. The mutation points shown in Table 1 are the drop points of $\mathrm{O}_{3}$ concentration, and it can be inferred that lower temperature, larger precipitation, shorter sunshine duration and higher relative humidity may reduce $\mathrm{O}_{3}$ concentration.

\section{Correlation Analysis}

\section{Meteorological Parameters}

In order to explore the influence of meteorological factors on $\mathrm{O}_{3}$ variation, the wavelet correlation spectrum was used based on $\mathrm{O}_{3}$ pollutant concentration and meteorological data in 2018. And the results are shown in Fig. 4.

\section{Temperature}

Fig. 4(a) presents the wavelet correlation spectrum between $\mathrm{O}_{3}$ concentration and daily mean temperature (DMT). As shown in figure, the disorder of phase characteristics between $\mathrm{O}_{3}$ concentration and DMT was increased as the period becomes higher, and the wavelet energy mainly concentrated in the period range of $0 \mathrm{~d}$ to $12 \mathrm{~d}$. With more particular reference to Fig. 4(a), the value of phase difference in May is $45 \pm 15^{\circ}$ at $0 \mathrm{~d}$ to $6 \mathrm{~d}$ scale which indicates the changes of $\mathrm{O}_{3}$ concentration lags behind DMT 1/8 $\pm 1 / 24$ period (about $0.5 \mathrm{~d}$ ), but the phase difference is small from August to September at $2 \mathrm{~d}$ to $6 \mathrm{~d}$ scale and the $\mathrm{O}_{3}$ concentration has a positive correlation with DMT (correlation coefficient > 0.7), additionally, there is no obvious time lag relationship from late February to April at $4 \mathrm{~d}$ to $8 \mathrm{~d}$ scale.

The relationship between $\mathrm{O}_{3}$ concentration and DMT may be further verified by analyzing Fig. 4(b). The mean value and median of $\mathrm{O}_{3}$ concentration increased gradually with the growth of the temperature, lower concentration mainly concentrated in the range of $\mathrm{T} \leq 15^{\circ} \mathrm{C}$ and the highest concentration appeared when $20^{\circ} \mathrm{C}<\mathrm{T} \leq 0^{\circ} \mathrm{C}$. Moreover, the over-standard rate of $\mathrm{O}_{3}$ increased obviously as temperature growing and reached a peak at $\mathrm{T}>30^{\circ} \mathrm{C}$, and there was a dramatic growth when $10^{\circ} \mathrm{C}<\mathrm{T} \leq 25^{\circ} \mathrm{C}$.

The results revealed that temperature has a positive correlation with $\mathrm{O}_{3}$, higher temperature accelerates the speed of photochemical reactions, causing an increase in the amount of $\mathrm{O}_{3}$.

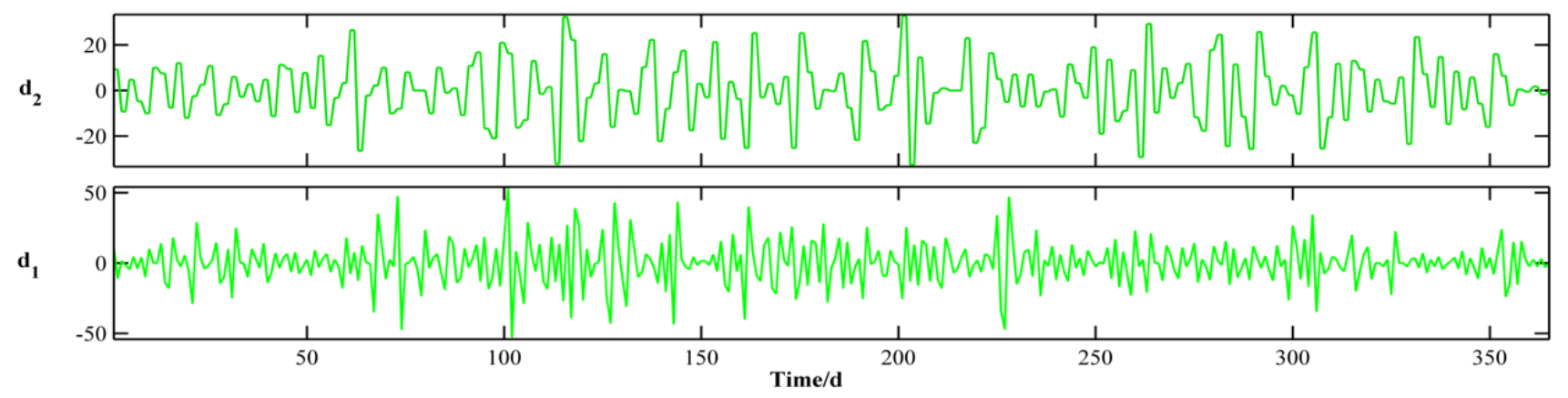

Fig. 3. High frequency signal at $1^{\text {st }}$ level and $2^{\text {nd }}$ level. 
Table 1. Meteorological data of the mutation day.

\begin{tabular}{llllllllll}
\hline $\begin{array}{l}\text { Mutation day and } \\
\text { corresponding date }\end{array}$ & $\begin{array}{l}\text { Current date } \\
\text { concentration } \\
\left(\mu \mathrm{g} \mathrm{m}^{-3}\right)\end{array}$ & $\begin{array}{l}\text { Previous day } \\
\text { concentration } \\
\left(\mu \mathrm{g} \mathrm{m}^{-3}\right)\end{array}$ & $\mathrm{WD}$ & $\begin{array}{l}\mathrm{RH} \\
(\%)\end{array}$ & $\begin{array}{l}\mathrm{WS} \\
\left(\mathrm{m} \mathrm{s}^{-1}\right)\end{array}$ & $\begin{array}{l}\mathrm{P} \\
(\mathrm{mm})\end{array}$ & $\begin{array}{l}\mathrm{T} \\
\left({ }^{\circ} \mathrm{C}\right)\end{array}$ & $\begin{array}{l}\mathrm{AP} \\
(\mathrm{hPa})\end{array}$ & $\begin{array}{l}\mathrm{SD} \\
(\mathrm{h})\end{array}$ \\
\hline $74 \mathrm{~d}(2018.3 .15)$ & 20 & 115 & $\mathrm{NNW}$ & 86 & 1.7 & 27.4 & 17.8 & $1,004.6$ & 0 \\
$102 \mathrm{~d}(2018.4 .12)$ & 69 & 175 & $\mathrm{SE}$ & 84 & 2.7 & 12.3 & 22.8 & $1,001.6$ & 0 \\
$127 \mathrm{~d}(2018.5 .7)$ & 50 & 101 & $\mathrm{~S}$ & 72.5 & 2.15 & 0 & 25.2 & $1,000.15$ & 6.5 \\
$143 \mathrm{~d}(2018.5 .23)$ & 94 & 142 & $\mathrm{NW}$ & 83 & 1.5 & 38.7 & 23.7 & 1002 & 0 \\
$161 \mathrm{~d}(2018.6 .10)$ & 63 & 107 & $\mathrm{SSE}$ & 78 & 1.7 & 8 & 24.2 & 992 & 1 \\
$227 \mathrm{~d}(2018.8 .15)$ & 37 & 60 & $\mathrm{NNW}$ & 89 & 3.2 & 37.4 & 26.6 & 992.1 & 0 \\
\hline
\end{tabular}

$\mathrm{WD}=$ wind direction; $\mathrm{RH}=$ relative humidity; $\mathrm{WS}=$ wind speed $; \mathrm{P}=$ Precipitation; $\mathrm{T}=$ Temperature; $\mathrm{AP}=$ air pressure; $\mathrm{SD}=$ sunshine duration.

\section{Solar Radiation}

Fig. 4(c) shows $\mathrm{O}_{3}$ concentration has positive significantly correlated relationship to the sunshine duration (SD; Fig. 4(c)). Looking more closely, wavelet energy distributed in most of the period, a large amount of wavelet energy appeared in June to December and the phase difference was $0 \pm 25^{\circ}, \mathrm{O}_{3}$ concentration and sunshine duration existed significant synergistic changes.

Like temperature, the $\mathrm{O}_{3}$ concentration presented synchronous increase trend with sunshine duration (Fig. 4(d)). In particular, as the sunshine duration grew, the mean value, the first quartile and the third quartile of $\mathrm{O}_{3}$ concentration had experienced process of continuous increased $(0 \mathrm{~h}<\mathrm{SD}$ $\leq 8 \mathrm{~h})$ and changed smoothly $(8 \mathrm{~h}<\mathrm{SD})$. Furthermore, the over-standard rate of $\mathrm{O}_{3}$ had a sharp rise from $21.30 \%(0 \mathrm{~h}$ $\leq \mathrm{SD} \leq 2 \mathrm{~h})$ to $84.21 \%(10 \mathrm{~h}<\mathrm{SD})$.

The change of temperature was closely correlated with the solar radiation, and the increase of sunshine duration is conducive to the accumulation of solar radiation energy. The rise of ambient temperature and solar energy can promote the photochemical reaction, accelerate the rate of $\mathrm{O}_{3}$ generation. Besides, the difference in sunshine duration was an important reason leading to the seasonal fluctuation of $\mathrm{O}_{3}$ variation.

\section{Relative Humidity}

Fig. 4(e) shows $\mathrm{O}_{3}$ concentration is significantly and negatively correlated with the daily mean relative humidity (DMRH). The energy regions with a correlation coefficient is greater than 0.8 occupies about $2 / 3$ of the figure. In particular, the distribution of wavelet energy was scattered and discontinuous at $0 \mathrm{~d}$ to $8 \mathrm{~d}$ scale, but energy distributed comparatively centralized at $0 \mathrm{~d}$ to $8 \mathrm{~d}$ and $>64 \mathrm{~d}$ scale and the phase difference was $0 \pm 25^{\circ}$, which indicated that the $\mathrm{O}_{3}$ concentration varied in a phase opposite to DMRH and there was a significantly negative correlation.

As can be seen in Fig. 4(f), the negative correlation between $\mathrm{O}_{3}$ concentration and relative humidity is further confirmed. Particularly, as relative humidity (RH; Fig. 4(f)), the lower mean value of $\mathrm{O}_{3}$ concentration occurred, and $\mathrm{RH}$ $=70 \%$ was a dividing point of the large fluctuations, and higher $\mathrm{O}_{3}$ concentration was mainly concentrated in the range of $\mathrm{RH}=40-70 \%$. Moreover, the exceeding rate of $\mathrm{O}_{3}$ was in a tendency of decrease $(\mathrm{RH} \geq 70 \%)$ and the rate reached zero when $\mathrm{RH} \geq 90 \%$.
The influence of relative humidity on $\mathrm{O}_{3}$ concentration is mainly represented in the following aspects: First, solar radiation will be attenuated by extinction mechanism under the action of water vapor, specifically, a large amount of water vapor tends to form clouds, thereby inhibiting ultraviolet rays reaching near the ground and delaying the occurrence of photochemical reactions. Second, in the case of high humidity, the free radicals $\mathrm{H}, \mathrm{OH}$, etc. contained in the water vapor rapidly decompose $\mathrm{O}_{3}$ into oxygen molecules, resulting in the reduction of $\mathrm{O}_{3}$ concentration (Wennberg et al., 1998). Third, high humidity can decrease $\mathrm{O}_{3}$ concentration by promoting the dry deposition (a process of atmospheric aerosol particles and trace gas components settling in the absence of precipitation).

\section{Precipitation}

In general, the wavelet coherence spectrum showed that a negative correlation existed between $\mathrm{O}_{3}$ concentration and daily mean precipitation (DMP) (Fig. 4(g)). It is noteworthy that the negative correlation was mainly reflected in spring and summer at $0 \mathrm{~d}$ to $16 \mathrm{~d}$ scale (correlation coefficient $>0.7$ ). Specifically, wavelet energy appeared in February to June and the phase difference was $180 \pm 20^{\circ}$ at $0 \mathrm{~d}$ to $16 \mathrm{~d}$ scale, which indicated the changes of $\mathrm{O}_{3}$ concentration lagged behind DMP 1/2 $\pm 1 / 12$ period (about 1-6 d), and the phase difference was $180 \pm 25^{\circ}$ at $48 \mathrm{~d}$ to $64 \mathrm{~d}$ scale, which showed that relations between $\mathrm{O}_{3}$ concentration and DMP were obvious antiphase changed.

As shown in Fig. 4(h), along with the precipitation (PR; Fig. 4(h)) increases, $\mathrm{O}_{3}$ concentration shows decreasing trend. The highest value of $\mathrm{O}_{3}$ concentration appears in the range of $\mathrm{PR} \leq 3 \mathrm{~mm}$, and the mean value of $\mathrm{O}_{3}$ concentration decreases continuously ( $\mathrm{PR} \leq 9 \mathrm{~mm}$ ) first and then declines slightly $(9 \mathrm{~mm}<\mathrm{PR})$. The exceeding rate of $\mathrm{O}_{3}$ decreased dramatically firstly ( $\mathrm{PR} \leq 9 \mathrm{~mm}$ ) and then increases slightly $(9 \mathrm{~mm}<\mathrm{PR} \leq 12 \mathrm{~mm})$, finally, dropped to low levels $(12 \mathrm{~mm}$ $<\mathrm{PR}$ ). It is obvious that precipitation has a significant elimination effect on ozone at $\mathrm{PR} \leq 9 \mathrm{~mm}$.

The precipitation has a certain influence on the $\mathrm{O}_{3}$ production process. In one aspect, the cloud layer is thicker during precipitation, which reduces the sunshine duration and temperature, and cloud layer scatters and absorbs solar radiation reaching the surface layer. In addition, precipitation has the effect of wet deposition, so that the $\mathrm{O}_{3}$ concentration on precipitation day is lower than that without precipitation. 


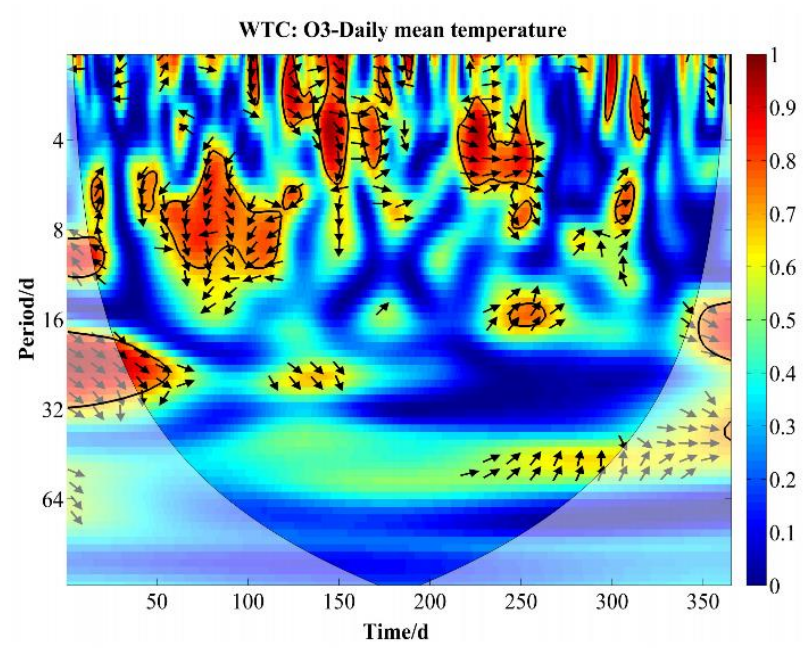

(a)

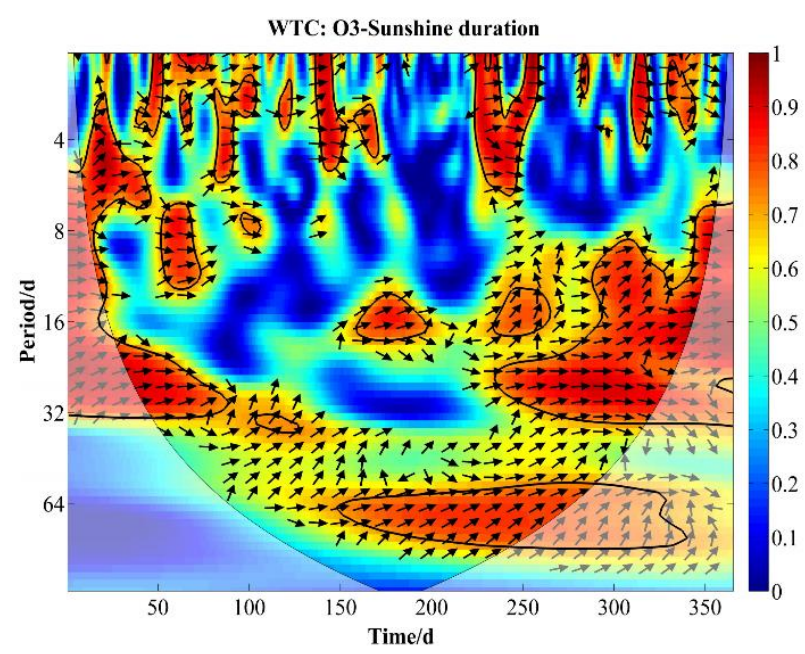

(c)

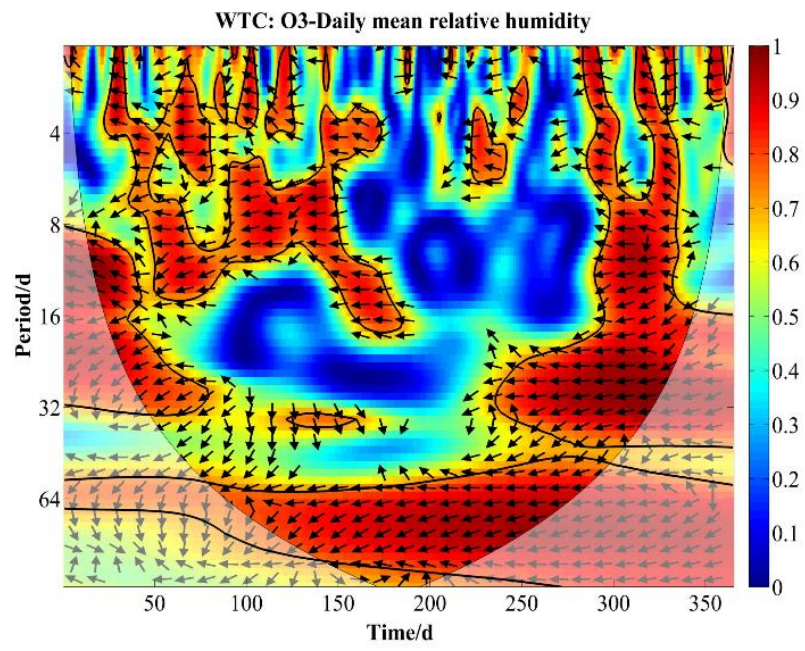

(e)

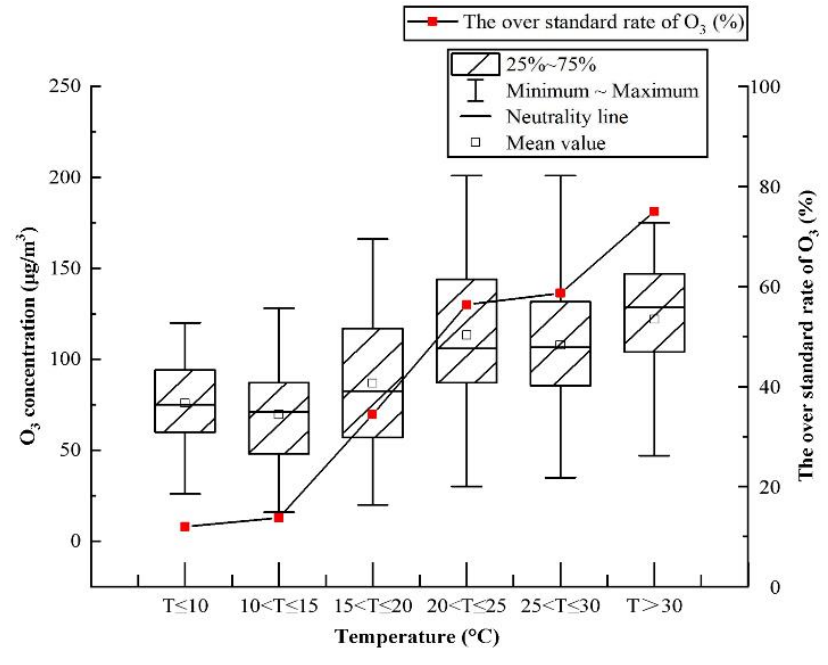

(b)

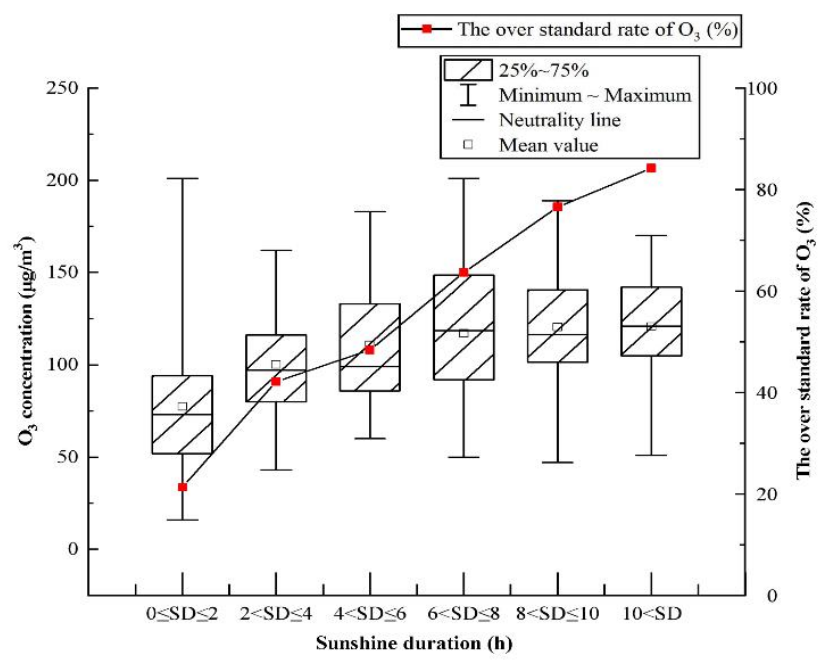

(d)

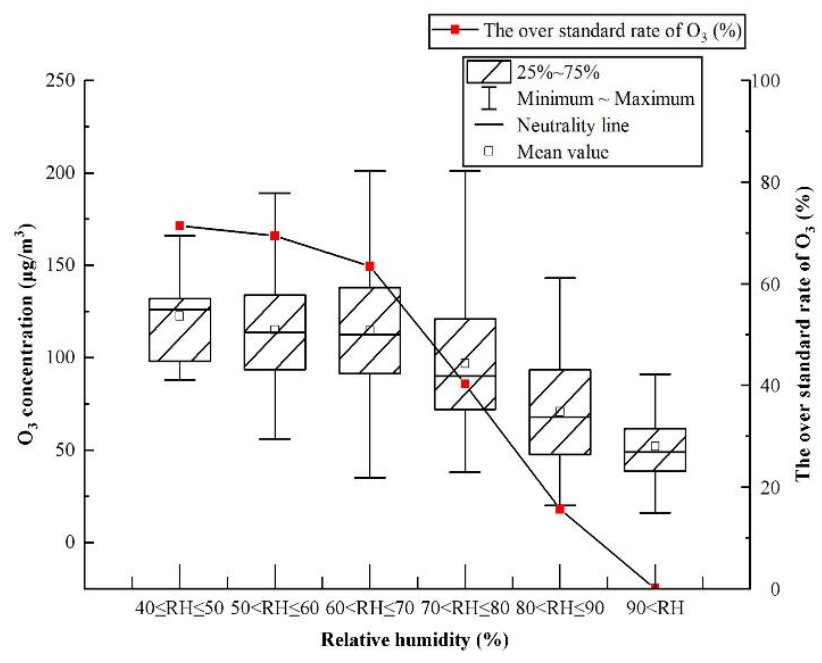

(f)

Fig. 4. The wavelet coherence spectrum (left) and the distribution of meteorological parameters (right). In the spectrum, the $5 \%$ significance level against red noise is shown as a thick contour, the relative phase relationship is shown as arrows (with in-phase pointing right, antiphase pointing left), and the orange represents a larger correlation coefficient and blue represents a smaller correlation coefficient. 


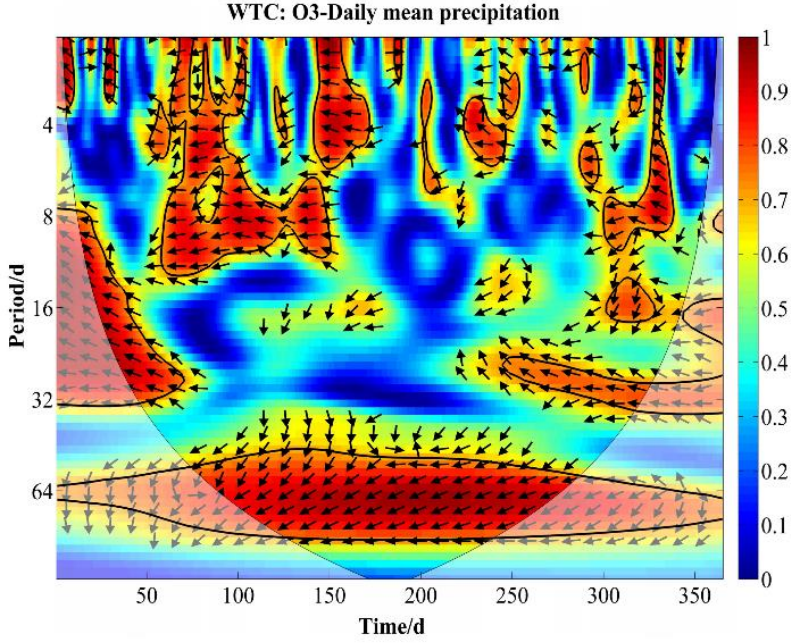

(g)

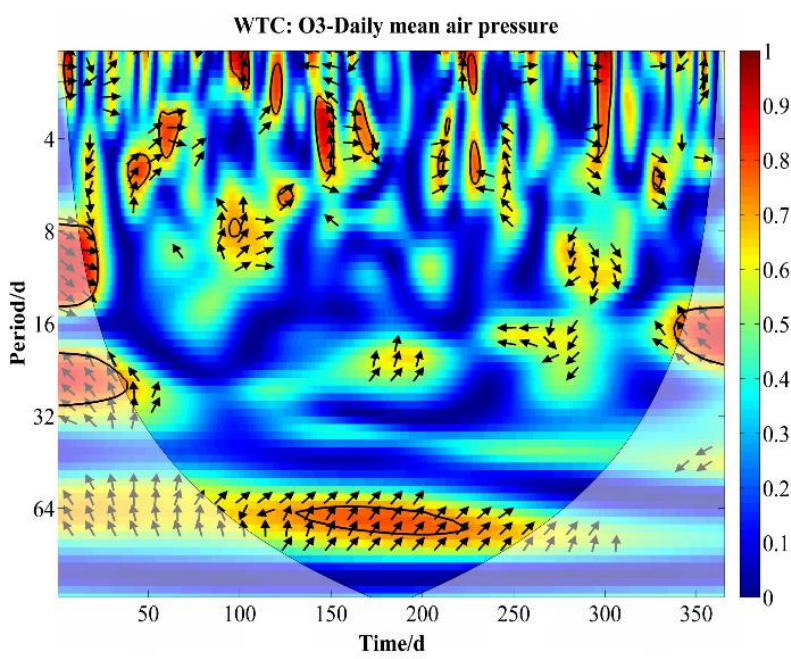

(i)

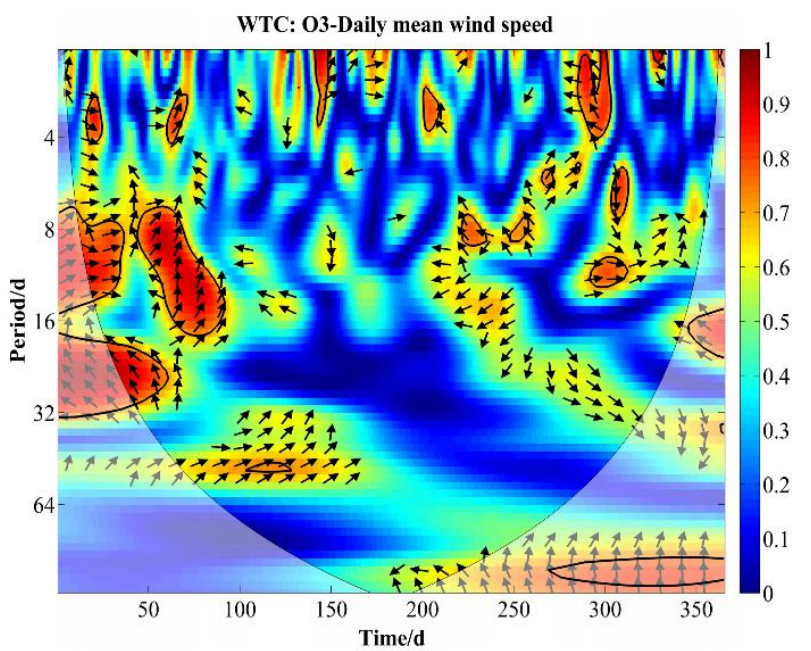

(k)

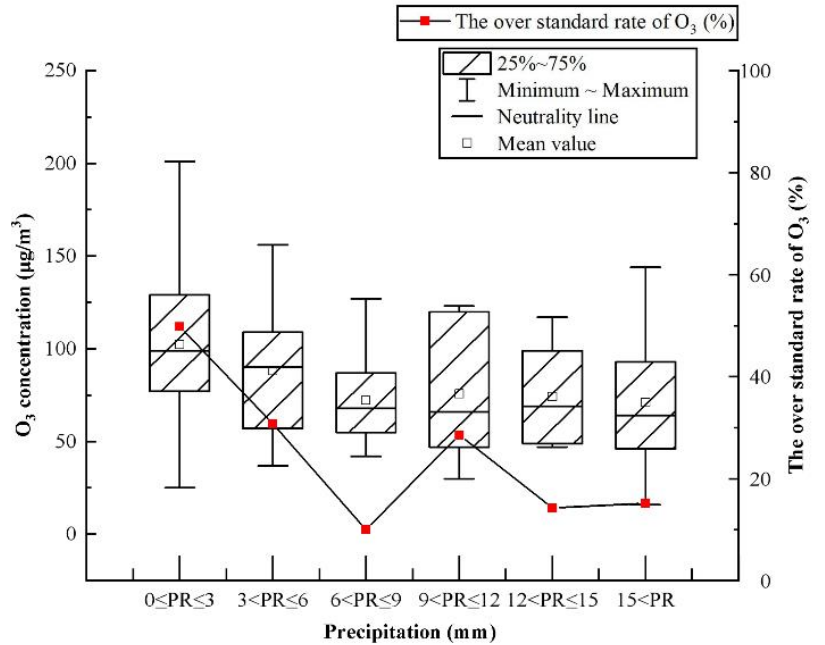

(h)

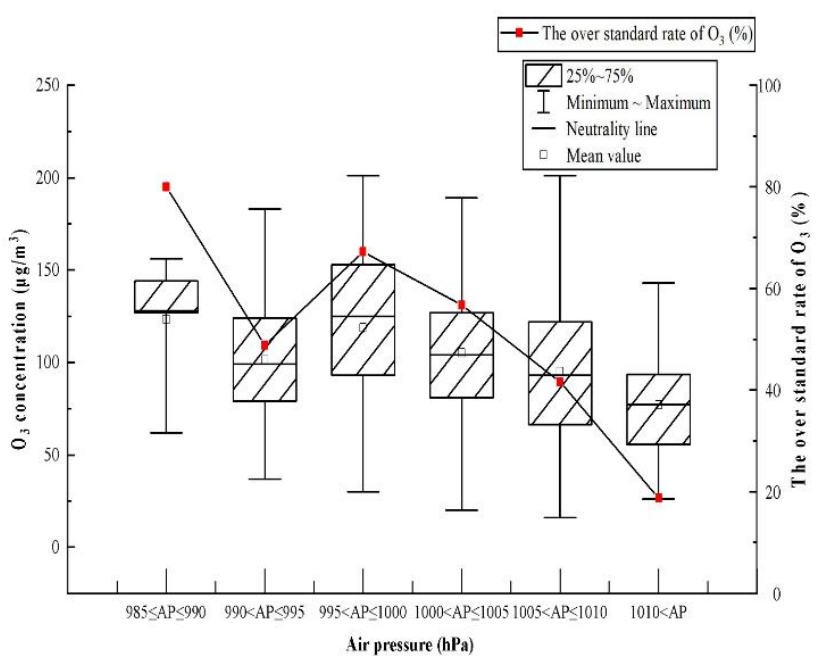

(j)

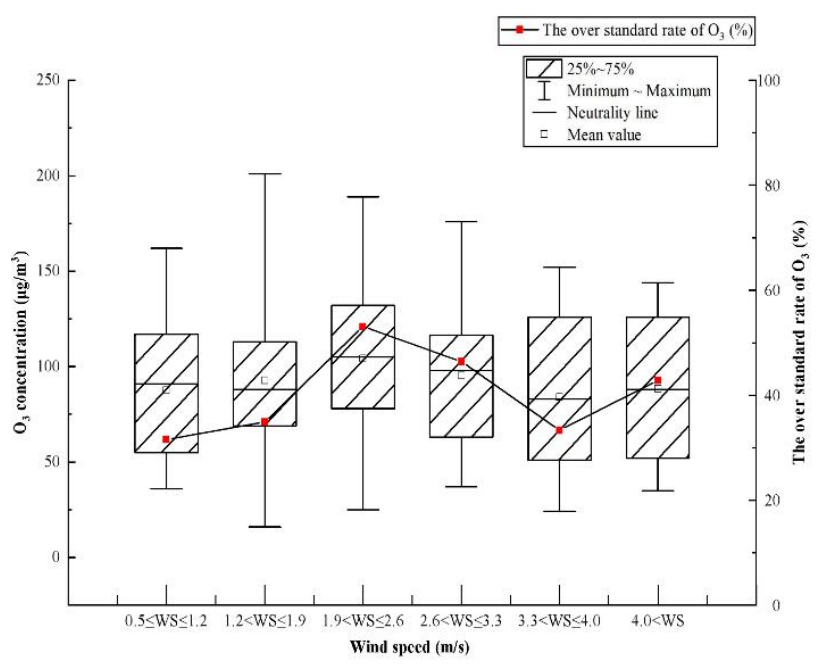

(1)

Fig. 4. (continued).

Air Pressure

Overall, Fig. 4(i) shows a low correlation between $\mathrm{O}_{3}$ concentration and daily mean air pressure (DMAP). The distribution of the wavelet energy region with correlation 
coefficient greater than 0.7 is scattered and the proportion of remarkable wavelet energy is small, therefore, no obvious correlation can be seen from the wavelet coherence spectrum.

However, it can be found in Fig. 4(j) that there is a negative correlation existed between $\mathrm{O}_{3}$ concentration and air pressure (AP; Fig. 4(j)). With the increase of air pressure, the mean value, the quartile and the exceeding rate of $\mathrm{O}_{3}$ concentration decreases at first $(\mathrm{AP} \leq 995 \mathrm{hPa})$, then increases $(995 \mathrm{hPa}<\mathrm{AP} \leq 1000 \mathrm{hPa})$, and decreased finally $(1000 \mathrm{hPa}$ $<$ AP). It is noteworthy that the over-standard rate of $\mathrm{O}_{3}$ decreases from $80 \%$ to $18.75 \%$, which shows a significantly negative correlation between $\mathrm{O}_{3}$ and air pressure.

\section{Wind Speed}

As can be seen in Fig. 4(k), significant correlation is not observed between $\mathrm{O}_{3}$ concentration and wind speed, the result is similar to the discussion of $\mathrm{O}_{3}$ concentration and DMAP.

Further studies were performed to explore the correlation between $\mathrm{O}_{3}$ concentration and wind speed (WS; Fig. 4(1)). Fig. 4(1) shows that the highest value of $\mathrm{O}_{3}$ concentration grows gradually first $\left(0.5 \mathrm{~m} \mathrm{~s}^{-1} \leq \mathrm{WS} \leq 1.9 \mathrm{~m} \mathrm{~s}^{-1}\right)$ and decreased continually $\left(1.9 \mathrm{~m} \mathrm{~s}^{-1}<\mathrm{WS}\right)$. Likewise, the relationship between the exceeding rate of $\mathrm{O}_{3}$ concentration and wind speed is not linear, decrease of the exceeding rate is obvious at $2.6 \mathrm{~m} \mathrm{~s}^{-1}<\mathrm{WS} \leq 4.0 \mathrm{~m} \mathrm{~s}^{-1}$, but the exceeding rate increases constantly in the low wind speed interval $\left(0.5 \mathrm{~m} \mathrm{~s}^{-1} \leq \mathrm{WS} \leq 2.6 \mathrm{~m} \mathrm{~s}^{-1}\right)$. In addition, the exceeding rate is maintained higher level at above $30 \%$ in all wind speed intervals.

The wind speed can not only reflect the efficiency of pollutant transport and atmospheric diffusion, but also reflect the intensity of stability in the atmospheric boundary layer to some extent. The change of $\mathrm{O}_{3}$ concentration with the increase of wind speed is mainly reflected in two aspects: First, as wind speed increases, the height of atmospheric boundary layer is elevated, the vertical momentum transport is strengthened, and then the $\mathrm{O}_{3}$ in the troposphere is transmitted to the ground layer. Second, the horizontal diffusion of $\mathrm{O}_{3}$ is enhanced. Moreover, when the wind speed is low $\left(0.5 \mathrm{~m} \mathrm{~s}^{-1} \leq \mathrm{WS} \leq 2.6 \mathrm{~m} \mathrm{~s}^{-1}\right)$, the horizontal diffusion of $\mathrm{O}_{3}$ is weaker than its downward transport effect, resulting in an increase of $\mathrm{O}_{3}$ concentration near the ground, but when the wind speed exceeds a certain value $\left(2.6 \mathrm{~m} \mathrm{~s}^{-1}<\mathrm{WS} \leq\right.$ $4.0 \mathrm{~m} \mathrm{~s}^{-1}$ ), the horizontal diffusion gradually dominates, and the $\mathrm{O}_{3}$ concentration will decrease significantly with the increase of wind speed. Besides, the $\mathrm{O}_{3}$ concentration fluctuation interval $\left(4 \mathrm{~m} \mathrm{~s}^{-1}<\mathrm{WS}\right)$ may be attributable to the stronger downward transport effect than the horizontal diffusion.

\section{Gaseous Precursor and Traffic Parameters}

The $\mathrm{NO}_{x}$ and $\mathrm{CO}$ contained in motor vehicle exhaust are precursors of $\mathrm{O}_{3}$, and exhaust emissions are closely related to real-time traffic conditions. Therefore, the precursors and traffic parameters were combined in this study. In addition, with the consideration of data acquisition, the pollutants and traffic hourly data (2017) were used, based on fitting and verifying the annual data of six monitoring stations, the data of typical working day (Wednesday, April 19, 2017) and rest day (Sunday, April 23, 2017) from Fujian Normal University monitoring station were taken as examples for analysis.

As can be seen from Fig. 5, the concentration of $\mathrm{NO}_{x}$ and $\mathrm{CO}$ changes with the similar tendency, and there is a significant negative correlation between the precursors and $\mathrm{O}_{3}$ on working day and rest day. On the working day, the initial concentrations of $\mathrm{NO}_{x}$ and $\mathrm{CO}$ are higher, both $\mathrm{NO}_{x}$ and CO drop gradually from 00:00 to 14:00, the valley values appear at 14:00 to 17:00, the fluctuation time periods of $\mathrm{NO}_{x}$ and $\mathrm{CO}$ are mainly concentrated at 05:00 to 10:00 and 17:00 to 19:00, moreover, the $\mathrm{O}_{3}$ concentrations remains steady at a low level before 07:00, increases sharply after 07:00, peaks in the time period from 12:00 to 13:00, and continues to decline after 16:00. In contrast, on the rest day, the initial concentration of $\mathrm{NO}_{x}$ and $\mathrm{CO}$ are lower than working day, and there is a significant fluctuation from 00:00 to 07:00. Additionally, unlike the working day, the $\mathrm{O}_{3}$ concentration on rest day gradually decreases from 00:00 to 04:00 and reaches the lowest value $\left(53 \mu \mathrm{g} \mathrm{m}^{-3}\right)$ at 04:00, increases continuously (04:00-12:00), and then maintains at a higher level (12:00-18:00), finally decreases gradually after 17:00.

As shown in Fig. 5, traffic parameters are closely related to $\mathrm{O}_{3}$ concentration, which also reflects the influence of real-time traffic conditions on the $\mathrm{O}_{3}$ concentration variation. On the working day, the vehicle flow (Q) and traffic flow density $(\mathrm{K})$ are at a low value before 07:00, the morning peak is from 07:00 to 09:00 and the vehicle flow in this period are greater than $1,000 \mathrm{veh} \mathrm{h}^{-1}$. According to the hydrodynamics simulation in traffic flow theory, when the traffic density increases due to the change of traffic conditions, the traffic flow wave will be generated in the traffic flow, and the traffic flow will experience the process of congestion to dissipation, therefore, the dissipating process of traffic flow occurred in both morning peak and evening peak (17:00-19:00). The vehicle speed (V) decreases as vehicle flow and traffic flow density increases, reaching a lower value in traffic peak period. The trend of $\mathrm{O}_{3}$ concentration shows a unimodal shape, and the higher value appears in $12: 00$ to $16: 00$. In contrast, on rest day, the morning peak and evening peak also exists, but the vehicle flow and traffic flow density are relatively small, vehicle flow between 07:00 to 19:00 maintains above 1,000 veh $\mathrm{h}^{-1}$ and there are multiple fluctuation intervals of vehicle speed and traffic flow density, this phenomenon may be attributable to the decrease of commuting and the increase of leisure travel on rest day, which results in a discrete traffic flow distribution. And the trend of $\mathrm{O}_{3}$ concentration on rest day displays roughly the same tendency with that on working day.

Under the influence of human activities, compared with working day, the concentration of precursors decreased at rest day, while the $\mathrm{O}_{3}$ concentration increased, and this phenomenon is called "weekend effect" (Cai et al., 2010). In this study, the weekend effect was obvious, in particular, the hourly mean value of $\mathrm{NO}_{x}$ concentration, $\mathrm{CO}$ concentration and vehicle flow decreased on rest day, 91 to $30 \mu \mathrm{g} \mathrm{m}^{-3}$, 1.10 to $0.71 \mathrm{mg} \mathrm{m}^{-3}$ and 824 to 778 veh $^{-1}$, respectively, 

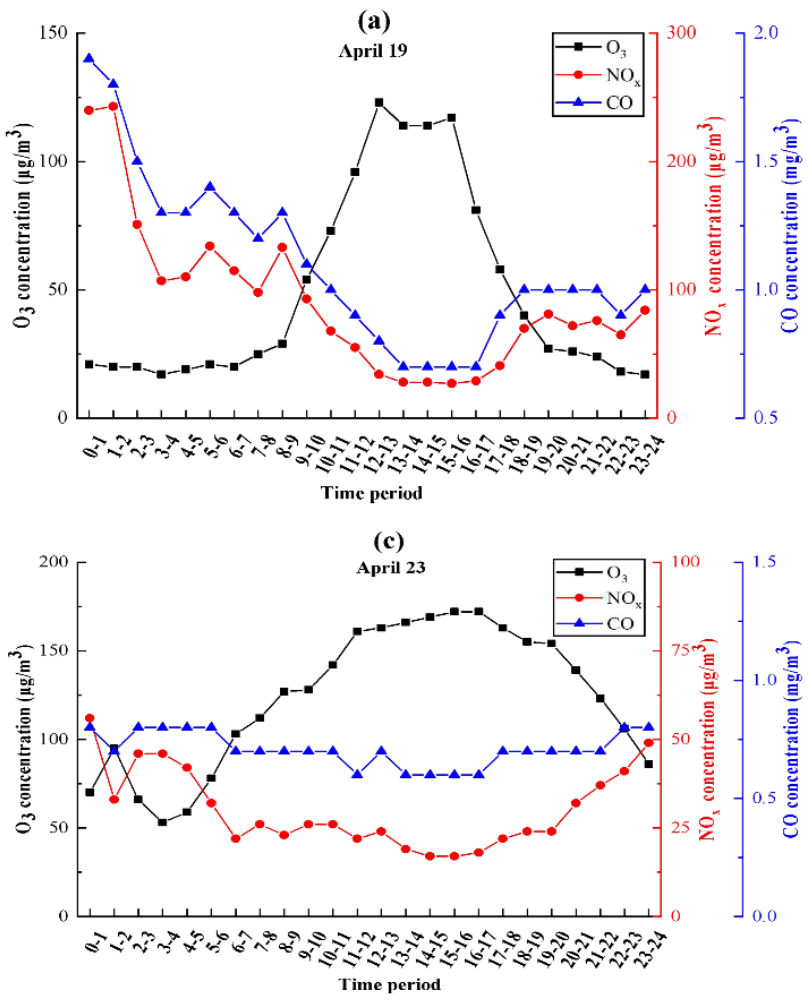
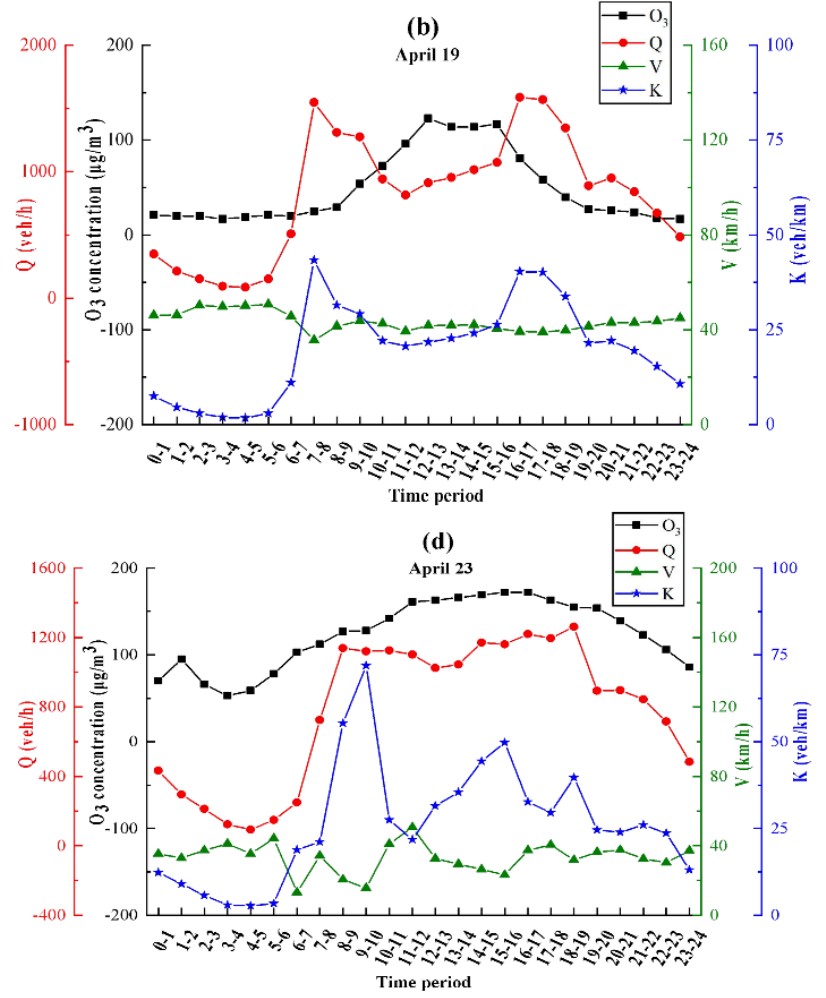

Fig. 5. Diurnal variation of $\mathrm{O}_{3}$, precursors and traffic parameters.

while $\mathrm{O}_{3}$ concentration increased from 49 to $123 \mu \mathrm{g} \mathrm{m}^{-3}$. This result was related to resident trip characteristics on the weekend, different travel patterns caused the change of traffic condition.

According to the traffic flow theory, the traffic flow is in a uninterrupted traffic state and the vehicle speed is high when the road is unobstructed, as the vehicle flow increases, the traffic flow density increases accordingly, the traffic flow turns to interrupted traffic when the vehicle flow reaches a certain value, and the phenomenon of car following occurs (Verhoef, 2005). It is known from the formation mechanism of vehicle exhaust that frequent acceleration, deceleration and idling state will result in incomplete combustion of fuel and the engine speed change (Chan et al., 1991), which leads to an increase in $\mathrm{NO}_{x}$ and $\mathrm{CO}$ emissions, therefore, the concentration of $\mathrm{NO}_{x}$ and $\mathrm{CO}$ fluctuated during morning and evening peak. Moreover, combined with the discussion in the previous section, the conditions of strong solar radiation, high temperature and low relative humidity can promote the photochemical reaction, which also explains that $\mathrm{NO}_{x}$ and $\mathrm{CO}$ were consumed from 09:00 to 17:00 and the precursor concentrations increased at night. Besides, the change of precursors at night was closely related to freight vehicles. Due to policy restrictions, the freight vehicles can only drive at a fixed time during the night, and the emission factor of freight vehicles (such as high tonnage diesel vehicles) is much higher than ordinary motor vehicles.

\section{CONCLUSIONS}

Our results, which confirm the advantages of analyzing time series of pollutant concentrations via wavelet transforms, indicate that meteorological factors, gaseous precursor levels and traffic conditions all contribute to the concentration of $\mathrm{O}_{3}$. The Ministry of Ecology and Environment should focus on the changes in $\mathrm{O}_{3}$ concentration during spring and summer and treat the control of precursors as the core of air pollution management, including vehicular emission reduction. However, the accuracy of our assessment may be hampered by our limited data. Hence, additional cities must be sampled and analyzed in the future, and a vehicular emission database that monitors the entire urban road network should be established in order to determine the relationship between traffic conditions and $\mathrm{O}_{3}$ pollution.

\section{ACKNOWLEDGEMENTS}

This study was sponsored by Natural Science Foundation Project of Fujian Province, China (No. 2018J01634); the Social Science Project of Fujian Province Education Department, China (No. JAS170150), and Science and Technology Innovation Project of Fujian Agriculture and Forestry University (No. CXZX2016038).

\section{REFERENCES}

Bureau of Statistics of Fuzhou (2018). Fuzhou statistical yearbook 2018. China Statistics Press. http://tjj.fuzhou.g ov.cn/zz/fztjnj/2018tjnj/indexch.htm

Cai, C., Geng, F., Tie, X., Yu, Q. and Junlin, A. (2010). Characteristics and source apportionment of VOCs measured in Shanghai, China. Atmos. Environ. 44: 5005- 
5014. https://doi.org/10.1016/j.atmosenv.2010.07.059

Chan, C.C., Oezkaynak, H., Spengler, J.D. and Sheldon, L. (1991). Driver exposure to volatile organic compounds, $\mathrm{CO}$, Ozone, and $\mathrm{NO}_{2}$ under different driving conditions. Environ. Sci. Technol. 25: 964-972. https://doi.org/10.10 21/es00017a021

Cheng, L., Wang, S., Gong, Z., Li, H., Yang, Q. and Wang, Y. (2018). Regionalization based on spatial and seasonal variation in ground-level ozone concentrations across China. J. Environ. Sci. 67: 179-190. https://doi.org/10.10 16/j.jes.2017.08.011

Colvile, R.N., Hutchinson, E.J., Mindell, J.S. and Warren, R.F. (2001). The transport sector as a source of air pollution. Atmos. Environ. 35: 1537-1565. https://doi.org/ 10.1016/S1352-2310(00)00551-3

Ercan, Ö., Dincer, F. and Ceylan, Ö. (2019). Spatial and seasonal variations of atmospheric BTEX, sulfur dioxide, nitrogen dioxide, and ozone concentrations in Istanbul, and health risk assessment of BTEX. Environ. Forensics 20: 149-161. https://doi.org/10.1080/15275922.2019.15 97775

Feng, Z., Hu, E., Wang, X., Jiang, L. and Liu, X. (2015). Ground-level $\mathrm{O}_{3}$ pollution and its impacts on food crops in China: A review. Environ. Pollut. 199: 42-48. https://doi.org/10.1016/j.envpol.2015.01.016

Hui, Z., Zheng, Y., Li, T., Wei, L. and Guan, Q. (2018). temporal and spatial variation in, and population exposure to summertime ground-level ozone in Beijing. Int. J. Environ. Res. Public Health 15: 628. https://doi.org/10.3 390/ijerph15040628

Jung, S.W., Lee, K., Cho, Y.S., Choi, J.H., Yang, W., Kang, T.S., Park, C., Kim, C.B. Yu, S.D. and Son, B.S. (2016). association by spatial interpolation between ozone levels and lung function of residents at an industrial complex in South Korea. Int. J. Environ. Res. Public Health 13: 728. https://doi.org/10.3390/ijerph13070728

Li, L., Xie, S., Zeng, L., Wu, R. and Li, J. (2015). Characteristics of volatile organic compounds and their role in ground-level ozone formation in the BeijingTianjin-Hebei region, China. Atmos. Environ. 113: 247254. https://doi.org/10.1016/j.atmosenv.2015.05.021

Li, Y., Cheng, M., Guo, Z., He, Y., Zhang, X., Cui, X. and Chen, S. (2020). Increase in surface ozone over BeijingTianjin-Hebei and the surrounding areas of China inferred from satellite retrievals, 2005-2018. Aerosol Air Qual. Res. https://doi.org/10.4209/aaqr.2019.11.0603

Lin, X., Yuan, Z., Yang, L., Luo, H. and Li, W. (2019). Impact of extreme meteorological events on ozone in the Pearl River Delta, China. Aerosol Air Qual. Res. 19: 1307-1324. https://doi.org/10.4209/aaqr.2019.01.0027

Liu, Y., Li, L., An, J., Huang, L., Yan, R., Huang, C., Wang, H., Wang, Q., Wang, M. and Zhang, W. (2018). Estimation of biogenic VOC emissions and its impact on ozone formation over the Yangtze River Delta region, China. Atmos. Environ. 186: 113-128. https://doi.org/10. 1016/j.atmosenv.2018.05.027

Pun, V.C. and Ho, K.F. (2019). Blood pressure and pulmonary health effects of ozone and black carbon exposure in young adult runners. Sci. Total Environ. 657:
1-6. https://doi.org/10.1016/j.scitotenv.2018.11.465

Qiao, X., Guo, H., Wang, P., Tang, Y., Ying, Q., Zhao, X., Deng, W. and Zhang, H. (2019). Fine particulate matter and ozone pollution in the 18 cities of the sichuan basin in Southwestern China: Model performance and characteristics. Aerosol Air Qual. Res. 19: 2308-2319. https://doi.org/10.4209/aaqr.2019.05.0235

Steiner, A., Luo, C., Huang, Y. and Chameides, W.L. (2002). Past and present-day biogenic volatile organic compound emissions in East Asia. Atmos. Environ. 36: 4895-4905. https://doi.org/10.1016/S1352-2310(02)00584-8

Tong, L., Zhang, J., Xu, H., Xiao, H., He, M. and Zhang, H. (2018). Contribution of regional transport to surface ozone at an island site of Eastern China. Aerosol Air Qual. Res. 18: 3009-3024. https://doi.org/10.4209/aaqr.2 017.11 .0508

Verhoef, E.T. (2005). Speed-flow relations and cost functions for congested traffic Theory and empirical analysis. Transp. Res. A 39: 792-812. https://doi.org/10.1016/j.tra. 2005.02.023

Wang, M.Y., Yim, S.H.L., Wong, D.C. and Ho, K.F. (2019). Source contributions of surface ozone in China using an adjoint sensitivity analysis. Sci. Total Environ. 662: 385392. https://doi.org/10.1016/j.scitotenv.2019.01.116

Wang, T., Xue, L., Brimblecombe, P., Lam, Y. F., Li, L. and Li, Z. (2017). Ozone pollution in China: A review of concentrations, meteorological influences, chemical precursors, and effects. Sci. Total Environ. 575: 15821596. https://doi.org/10.1016/j.scitotenv.2016.10.081

Weng, D., Yin, Y. and Yang, D. (2011). Singular points detection based on multi-resolution in fingerprint images. Neurocomputing 74: 3376-3388. https://doi.org/10.1016/ j.neucom.2011.05.023

Wennberg, P.O., Hanisco, T.F., Jaegle, L., Jacob, D.J., Hintsa, E.J., Lanzendorf, E.J., Anderson, J.G., Gao, R.S., Keim, E.R., Donnelly, S.G., Del Negro, L.A., Fahey, D.W., McKeen, S.A., Salawitch, R.J., Webster, C.R., May, R.D., Herman, R.L., Proffitt, M.H., Margitan, J.J., ... Bui, T.P. (1998). Hydrogen radicals, nitrogen radicals, and the production of $\mathrm{O}_{3}$ in the upper troposphere. Science 279: 49-53. https://doi.org/10.1126/science.279. 5347.49

Wu, J.B., Wang, Q., Chen, H., Zhang, Y. and Wild, O. (2017). On the origin of surface ozone episode in Shanghai over Yangtze River Delta during a prolonged heat wave. Aerosol Air Qual. Res. 17: 2804-2815. https://doi.org/10.4209/aaqr.2017.03.0101

Zhang, L., Lin, J., Qiu, R., Hu, X., Zhang, H., Chen, Q., Tan, H., Lin, D. and Wang, J. (2018). Trend analysis and forecast of $\mathrm{PM}_{2.5}$ in Fuzhou, China using the ARIMA model. Ecol. Indic. 95: 702-710. https://doi.org/10.1016/ j.ecolind.2018.08.032

Zhang, T., Lin, W., Ran, L., Ma, Z., Yao, Q., Liu, J. and Ming, J. (2020). Two-height distribution of ozone and nitrogen oxides during summer in Urban Tianjin, China: An observational study. Aerosol Air Qual. Res. https://doi.org/10.4209/aaqr.2019.10.0505

Zhang, Y.H., Su, H., Zhong, L.J., Cheng, Y.F., Zeng, L.M., Wang, X.S., Xiang, Y.R., Wang, J.L., Gao, D.F., Shao, 
M., Fan, S.J. and Liue, S.C. (2008). Regional ozone pollution and observation-based approach for analyzing ozone-precursor relationship during the PRIDEPRD2004 campaign. Atmos. Environ. 42: 6203-6218. https://doi.org/10.1016/j.atmosenv.2008.05.002

Zheng, J., Zhong, L., Wang, T., Louie, P.K.K. and Li, Z. (2010). Ground-level ozone in the Pearl River Delta region: Analysis of data from a recently established regional air quality monitoring network. Atmos. Environ. 44: 814823. https://doi.org/10.1016/j.atmosenv.2009.11.032

Received for review, December 27, 2019

Revised, June 9, 2020

Accepted, June 14, 2020 